\title{
Strategies of information search in causal analysis
}

\author{
HARRIET SHAKLEE \\ University of Iowa, Iowa City, Iowa 52242 \\ and \\ BARUCH FISCHHOFF \\ Decision Research, Perceptronics, Eugene, Oregon 97401
}

\begin{abstract}
Five experiments investigated the relative prevalence of three search patterns that individuals may use in explaining events with multiple possible causes: (1) parallel searchpursue information about all possible causes before making any causal judgments, (2) serial search-clarify the role of one cause before considering any others, (3) truncated searchclarify the role of one cause without proceeding to consider other causes. In Experiments 1, 2, and 3, subjects were told about an event, two or three nonexclusive possible causes of the event, and a fact implicating one of the suggested causes as influencing the event. Subjects were asked for the question whose answer would help them most in explaining the event. In each experiment, subjects preferred to clarify the role of the implicated cause, a pattern congruent with both the serial and truncated search strategies. Results of a fourth experiment indicated that these preferences reflect a truncated rather than a serial search. A final experiment demonstrated that the preference for information about the implicated cause persists even with the opportunity for a more extended search.
\end{abstract}

Testing hypotheses about the causes of events may be conceptualized as a process of uncertainty reduction. An event occurs that may be the product of several possible causes. The observer searches for information until relatively certain about the nature of the cause-effect relationship at hand. At that point, the individual may either draw conclusions about the hypotheses (or causes) being considered or continue the information search.

Most research regarding such hypothesis testing has focused on cases in which only one of a set of possible causes may be involved in the event. Results suggest several common shortcuts that people take when searching for information relevant to such mutually exclusive hypotheses. First, their search is rarely exhaustive. That is, people tend to ask for only a subset of the information relevant to any single cause-effect relationship (e.g., Hansen, 1980; Major, 1980). In particular, people frequently focus on only one of the possible relationships, ignoring information relevant to alternative

Partial support for this research was provided by the Advanced Research Projects Agency of the Department of Defense and was monitored by the Office of Naval Research under Contract N00014-79-C-0029 (ARPA Order No. 3668) to Perceptronics, Inc., by the Office of Naval Research under Contract N00014-80-C-0150 to Perceptronics, Inc., and by National Institute of Education Grant NIE-G-80-0091. Our thanks to Ruth Beyth-Marom, Pau1 Slovic, and several anonymous reviewers for useful comments on earlier drafts. Correspondence should be sent to Harriet Shaklee, Department of Psychology, University of lowa, Iowa City, Iowa 52242. possible accounts (e.g., Major, 1980; Taplin, 1975). Of course, when there are only two mutually exclusive hypotheses, there may be nothing wrong with focusing on a single hypothesis. For example, when asked to determine if an individual is an introvert or extravert, subjects have been observed to prefer asking questions that would tell them about one or the other of the two traits (Snyder \& Swann, 1978). In this case, evidence that confirms one hypothesis equivalently disconfirms the other hypothesis. Thus, focusing the search on one hypothesis may simply facilitate information processing.

Another tendency in information search may, however, pose a considerable threat to explanatory accuracy. This is the confirmatory bias observed among subjects dealing with multiple possible hypotheses in testing a rule or logical relationship (Schustack \& Sternberg, 1981; Wason \& Johnson-Laird, 1972). Subjects in these experiments tended to collect (or rely on) information that could confirm the rule to be tested, ignoring potentially disconfirmatory information. Having seen only a subset of the relevant data, such an individual risks prematurely accepting a rule that does not account for potentially observable data.

However, causes in the real world frequently are not mutually exclusive. That is, an event may have several possible sources, each of which would be sufficient to produce the event. For example, a student who fails a math test may attribute that performance to being ill at the time, to having gotten behind in homework, to having a poor instructor, and/or to having a poor facility 
for mathematics. Any one of these causes would be sufficient to result in low performance, as would any subset of the causes acting in combination. Attribution theorists refer to such relationships as reflecting multiple sufficient causes (Kelley, 1972b). Such relationships are more difficult to understand than cases involving mutually exclusive causes. When multiple sufficient causes are possible, relative certainty about the role of any single cause does not justify termination of the information search. Rather, the individual must search for information relevant to each cause before reaching a conclusion about the true nature of the cause-effect relationships.

Studies of reasoning about multiple sufficient causes have adopted a common design. Subjects are asked to judge the likelihood that a given cause is present when a second cause is reported either as being present or as being absent. The typical outcome of these experiments is that subjects estimate that a given cause is less likely to be present when alternative explanations are tenable (e.g., Jones \& Davis, 1965; Jones \& McGillis, 1976; Kelley, 1972a). The commonly proposed account of this effect (termed "discounting") was suggested by Kelley (1972a, 1972b): People learn through experience that each of several causes may be sufficient to produce a given event. If that event occurs with only one possible cause present, the attributor can be fairly confident about its role in the event. However, the presence of alternative causes renders the role of any one cause ambiguous. In this view, discounting reflects subjects' appreciation of the uncertainty inherent in multicausal situations.

However, a lower likelihood judgment need not reflect increased uncertainty. Subjects may also judge the second cause as less likely because they have rejected it as an event contributor. Such subjects may feel quite certain about the relative roles of both causes. At least two discounting studies suggest that subjects are relatively confident about the absence of the second cause (Kun, Murray, \& Sredl, 1980; Smith, 1975). Thus, the same discounting paradigm has produced data that can be interpreted as reflecting both increased and decreased uncertainty about causal relations.

In a complete causal analysis, all potential contributors must be considered before an event is fully accounted for. Subjects thus should search for information relevant to a possible cause as long as they are uncertain about its role in the event. Such a thorough search for causal information is implied by Kelley's (1967) ANOVA model. According to that model, people simultaneously consider an entire set of possible causes, represented as factors in an analysis of variance matrix. They collect and review the evidence relevant to all causes before passing judgment on the role of any. We will call this strategy "parallel search."

The obvious alternative to parallel search might be called "serial search." An individual using this strategy would collect evidence relevant to a single cause until he or she is relatively certain about its role in the event.
At that point, evidence relevant to another possible cause is collected, and so on. The serial strategy has the advantage of allowing the searcher to focus attention on one cause at a time. Parallel and serial search would lead to the same conclusions about cause-effect relationships if the serial strategy were pursued until all possible explanations had been investigated.

A third approach to causal analysis would involve stopping such a serial information search as soon as the contributory involvement of any one sufficient cause had been established. Once one cause has been identified as a favorite, the individual would implement this strategy most efficiently by searching for evidence clarifying the role of that cause in the event. Unless the favored hypothesis proved to be wrong, information about alternative causes would be irrelevant to this strategy; it would not be sought and possibly would not be noted if it were inadvertently uncovered. The result would be a sufficient rather than a complete account of the event, with multiply caused events simplified to a single adequate explanation. We term this pattern "truncated search." A truncated search might mean that the individual had rejected the other possible causes as potential contributors. Alternatively, having identified one sufficient cause, the searcher may be willing to tolerate uncertainty about the additional potential contributors. Such an incomplete search could easily mislead one by obscuring relevant information. ${ }^{1}$

Five experiments were designed to investigate the prevalence of these three patterns of information search among individuals asked to explain everyday events. The first three experiments distinguished parallel search patterns from those associated with serial and truncated searches. Participants were told about an event and about several possible causes. A fact was then given that directly implicated one possible cause. Subjects were asked what information they would most like to know in order to explain the event. Parallel searchers should continue to be interested in all possible causes and have no particular preference for knowing more about the cause already implicated. In contrast, serial and truncated searchers should want to know more about the implicated cause, thereby clarifying its role.

In the first experiment, we asked for subjects' preferred questions in a free response format. Allowing subjects to respond freely gives the best index of judgment patterns as they are most likely to occur in the similarly unconstrained natural environment (Fischhoff, 1976). Subsequent experiments explore the details of the strategies with more readily controlled forcedchoice tasks.

\section{EXPERIMENT 1}

\section{Method}

Stimuli. Each item consisted of a sentence describing an event. Two possible causes were suggested for half of the 24 events, and three were suggested for the other half. Each possible cause was potentially a sufficient account of the event; possible 
causes for each event were not mutually exclusive. For each item, a fact was listed implicating one of the possible causes as a likely contributor to the event, for example, "Event: Laura bought a pantsuit. Possible Cause A: She needed more clothes she could wear to work. Possible Cause B: The pantsuit was on sale. Fact: She was on her first job out of college."

All 24 items appeared on each of two forms with the twoand three-alternate-cause items intermixed in no particular order. For each item, the facts on Form 1 implicated one possible cause, whereas the facts on Form 2 implicated another possible cause.

Pretest. An initial sample of 49 subjects identified, for each item, the possible cause most implicated by the fact. Facts in Form 1 were evaluated by 18 people; Form 2 facts were judged by 31 people. Consensus was defined as having at least twothirds of these judges agree on which cause was implicated by the fact. Four items failed to reach the criterion, two on each form. Events, possible causes, and facts for these items are listed in the appendix. Mean agreement on the remaining items was $87.8 \%$. Although all 24 items remained in the questionnaire, reponses to these four low-consensus items were ignored in data analyses.

Instructions. The following instructions accompanied the items:

"Each of the problems in this booklet describes an event, a fact about that event, and several possible causes of that event. Your task is to explain why the event occurred.

"We would like you to list a question whose answer would most help you to explain the event (other than the question: Why did it happen?).'

Due to the time-consuming nature of this free response format, the 24 items were divided into two sets of 12 items (Sets A and B), creating four different experimental questionnaires. Forms $A 1$ and $A 2$ listed the same items, but facts on the two forms implicated different causes for each item. Forms B1 and B2 followed the same pattern for the remaining items.

Subjects. Subjects were recruited by an advertisement in a university student newspaper offering payment for participation in an experiment; 29 subjects responded to Form A1, 26 to Form A2, 40 to $B 1$, and 40 to B2.

\section{Results}

Responses were reviewed by two raters unaware of the purpose of the experiment. Each rater independently categorized subjects' questions according to whether they asked about Cause A, Cause B, or Cause C (when there were three causes), whether they asked for a clarification of the fact, or whether none of the preceding categories fit. The raters agreed on $71 \%$ of their ratings. The following analyses are based on those questions about which the raters agreed. Analyses using only the categorizations of either of the two raters produced substantially the same conclusions.

Table 1 shows the total number of questions falling into each category. These may be interpreted in several ways. With two-cause items, $61.8 \%$ [136/(136+84)] of the questions directed at either cause were directed at the one implicated by the fact. Questions asking for a clarification of the fact might either be ignored or be taken as an indication of the nonparallel strategies, since clarifying that fact will, presumably, tell more about the involvement of the cause it implicates. By this interpretation, $73.2 \%[(136+94) /(136+84+94)]$ of the requests demonstrated this nonparallel pattern. Responses falling into "other" represent a hodgepodge of replies that is not readily interpreted.

With three-cause items, the number of questions concerning the implicated cause equaled the number of questions concerning the two other causes combined. If subjects were equally interested in all three causes (i.e., were using a parallel strategy), twice as many questions regarding nonimplicated causes would be expected. If questions about the fact are interpreted as being about the implicated cause, $65.8 \%$ of the questions were consistent with a nonparallel search.

The tallies in Table 1 contain many dependent data, since each subject contributed $3.10($ mean $=7.0)$ responses upon whose interpretation the raters agreed. Table 2 characterizes each subject according to the predominant preference in the questions he or she asked, for two- and three-cause items separately. Subjects were considered predominantly nonparallel if they were more likely than chance to ask for further information about the implicated cause. Two separate analyses were done, one ignoring requests to clarify the reported fact and one treating such requests as a form of nonparallel search. When fact-clarification questions were ignored, chance was defined as $50 \%$ of questions for two-cause items and $33 \%$ for three-cause items. When factclarification questions were included, chance levels were set at $67 \%$ for two-cause items and $50 \%$ for threecause items. By either of these interpretations, the great majority of subjects were predominantly nonparallel

Table 1

Number of Questions Asked (N) and Percentages (P): Experiment 1

\begin{tabular}{|c|c|c|c|c|c|c|c|c|c|c|c|c|c|c|c|c|}
\hline & \multicolumn{8}{|c|}{ Two-Cause Items } & \multicolumn{8}{|c|}{ Three-Cause Items } \\
\hline & \multicolumn{2}{|c|}{$\mathrm{CI}$} & \multicolumn{2}{|c|}{ CNI } & \multicolumn{2}{|c|}{$\mathbf{F}$} & \multicolumn{2}{|c|}{0} & \multicolumn{2}{|c|}{ CI } & \multicolumn{2}{|c|}{ CNI } & \multicolumn{2}{|c|}{ F } & \multicolumn{2}{|c|}{0} \\
\hline & $\mathbf{N}$ & $\mathbf{P}$ & $\mathrm{N}$ & $\mathbf{P}$ & $\mathbf{N}$ & $\mathbf{P}$ & $\mathbf{N}$ & $\mathbf{P}$ & $\mathbf{N}$ & $\mathbf{P}$ & $\mathrm{N}$ & $\mathbf{P}$ & $\mathrm{N}$ & $\mathbf{P}$ & $\mathbf{N}$ & $\mathbf{P}$ \\
\hline $\begin{array}{l}\text { A1 } \\
\text { A2 } \\
\text { B1 } \\
\text { B2 }\end{array}$ & $\begin{array}{l}40 \\
36 \\
31 \\
29\end{array}$ & $\begin{array}{l}37 \\
44 \\
32 \\
26\end{array}$ & $\begin{array}{l}20 \\
15 \\
14 \\
35\end{array}$ & $\begin{array}{l}19 \\
18 \\
14 \\
32\end{array}$ & $\begin{array}{r}15 \\
9 \\
40 \\
20\end{array}$ & $\begin{array}{l}14 \\
11 \\
41 \\
18\end{array}$ & $\begin{array}{l}32 \\
22 \\
12 \\
26\end{array}$ & $\begin{array}{l}30 \\
27 \\
12 \\
24\end{array}$ & $\begin{array}{l}36 \\
24 \\
53 \\
34\end{array}$ & $\begin{array}{l}32 \\
23 \\
33 \\
24\end{array}$ & $\begin{array}{l}35 \\
30 \\
31 \\
51\end{array}$ & $\begin{array}{l}31 \\
29 \\
19 \\
35\end{array}$ & $\begin{array}{l}28 \\
33 \\
51 \\
25\end{array}$ & $\begin{array}{l}25 \\
32 \\
32 \\
17\end{array}$ & $\begin{array}{l}14 \\
16 \\
25 \\
34\end{array}$ & $\begin{array}{l}12 \\
16 \\
16 \\
24\end{array}$ \\
\hline Total & 136 & 33 & 84 & 21 & 94 & 23 & 92 & 23 & 147 & 28 & 147 & 28 & 137 & 26 & 89 & 17 \\
\hline
\end{tabular}

Note-CI = question about cause implicated by fact; $C N I=$ question about cause not implicated by fact; $F=$ question about fact; $O=$ other. 
Table 2

Number of Subjects Predominantly Asking Questions About Implicated and Nonimplicated Causes: Experiment 1

\begin{tabular}{lccccc}
\hline & \multicolumn{2}{c}{$\begin{array}{c}\text { Two-Cause } \\
\text { Items }\end{array}$} & & \multicolumn{2}{c}{$\begin{array}{c}\text { Three-Cause } \\
\text { Items }\end{array}$} \\
\cline { 2 - 3 } \cline { 5 - 6 } $\begin{array}{c}\text { Questions Predominantly } \\
\text { About: }\end{array}$ & 1 & 2 & & 1 & 2 \\
\hline Implicated Cause & 54 & 71 & & 77 & 83 \\
No Preference & 18 & 11 & & 12 & 26 \\
Nonimplicated Cause & 28 & 39 & & 32 & 22 \\
\hline
\end{tabular}

Note $-1=$ ignoring requests for clarification of fact $; 2=$ treating requests to clarify fact as referring to implicated cause.

processors. Sign tests contrasting the two question preference patterns were highly significant for twocause and three-cause items, using either interpretation of "questions about fact" ( $z>6$ in all cases).

\section{EXPERIMENT 2}

Experiment 1 suggested a substantial preference for serial or truncated information search under circumstances in which subjects could formulate their own questions. Thus, subjects show consistent search patterns when they can choose from the entire universe of possible questions. However, free response evidence comes at some cost. Specifically, the stability of these search patterns is somewhat qualified by the modest reliability in categorizing subjects' questions. Although the same pattern of results emerged when considering each rater's categorizations separately as when looking at the items about which the two raters agreed, an experiment with a more controlled response format seemed desirable.

In Experiment 2, subjects read about an event with two or three possible causes and then selected the one question (from a set of options) that they would like answered in order to help them explain the event. Each question was relevant to clarifying the role of one of the possible causes. The no-fact group selected their question with no knowledge of any implicating facts. Their choices afford a measure of the inherent interest of questions and plausibility of causes. Fact groups knew about a fact implicating one of the causes at the time they made their selection. As in Experiment 1, nonparallel searchers should more frequently select questions relevant to the implicated causes, whereas parallel searchers should not single out such questions.

Aside from facilitating data analysis, the use of prepared questions also eliminates one possible explanation for the results of Experiment 1. Providing a fact relating to one cause may make it easier to formulate questions relevant to that cause. Here, questions relevant to each cause were readily available.

\section{Method}

Stimuli. Events, causes, and facts were the same as those used in Experiment 1. For each possible cause, a question was developed asking for information relevant to that cause. Some of the questions were taken from subjects' responses in Experiment 1 ; others were generated by the experimenters.

Pretest. All questions were pretested for their judged relevance to the possible causes. For each item, 56 subjects identified the cause to which each question referred. Items were retained if at least $90 \%$ of the subjects agreed on the referent of each question. Only one item failed to meet this criterion. The remaining 19 questions were assembled into a questionnaire. (See the appendix for the complete listing of items.)

Instructions. As in Experiment 1, one form of the questionnaire included items with facts relevant to one of the causes (Fact 1). The second form included facts implicating another of the causes (Fact 2). A third form presented the same items with no fact presented (no fact). Since this task was appreciably easier than that of Experiment 1, items were not separated into $A$ and $B$ sets. The instructions subjects were given are shown in Figure 1 .

Subjects. Participants were undergraduates in an introductory psychology class who participated in the experiment as one option in fulfillment of a course requirement: Thirty-eight responded to Fact 1, 36 to Fact 2, and 37 to the no-fact form.

\section{Results}

Selections were tallied for each question of each item. With 19 events and two different causes implicated on the two forms, there are 38 possible cases for analysis.

The impact of the factual information is best assessed by comparing subjects' question preferences in the fact and no-fact conditions. For 37 of the 38 comparisons, fact subjects, who had received factual information implicating a cause, were more likely to select the question relevant to that cause than were no-fact subjects. Over all 38 cases, fact subjects selected the question about the implicated cause $78.3 \%$ of the time, compared to $43.6 \%$ selecting the same questions when no fact was given. ${ }^{2}$

Table 3 summarizes the size of these preference shifts for the 38 cases; $\mathrm{X}$ equals the percentage of fact subjects selecting the question about an implicated

Each of the problems in this booklet describes an event and several possible causes of that event. Your task is to explain why the event occurred

Event: Jim was arrested for speeding.

Possible Cause A: He has a penchant for fast driving.

Possible Cause B: He was late.

Possible Cause C: He was framed.

Fact: He has a sports car. [omitted on no-fact form]

After each event, two or three questions about that event are listed. For example, for the above item, you might have questions:

Question 1: What's Jim's past speeding record?

Question 2: Was the arresting officer short on the number of traffic citations he'd given that night?

Question 3: When was Jim supposed to be at his destination?

Your task is to identify which of those questions you would most like to have answered in trying to explain why Jim was arrested for speeding. In the space provided for each item, write the number $(1,2$, or 3$)$ of the question you'd most like answered in explaining the event. 
Table 3

Differences Between the Percentage of Fact and No-Fact Subjects Selecting the Question About Implicated Cause (=X): Experiment 2

\begin{tabular}{rc}
\hline Difference & Frequency \\
\hline$X \leqslant 0 \%$ & 1 \\
$0 \%<X \leqslant 15 \%$ & 5 \\
$15 \%<X \leqslant 30 \%$ & 10 \\
$30 \%<X \leqslant 45 \%$ & 10 \\
$45 \%<X \leqslant 60 \%$ & 5 \\
$60 \%<X$ & 7 \\
\hline
\end{tabular}

cause minus the percentage of no-fact subjects selecting that question. Twenty-five of these comparisons were significantly different (chi-square test, $\alpha=.05$ ); all but one of these significant comparisons was in the direction of nonparallel search.

Reponse patterns within question sets followed the same pattern. For 36 of the 38 cases, subjects chose the question relating to the implicated cause more frequently than any other question. Subject-by-subject analyses revealed greater than chance preference for such nonparallel search questions for $96 \%$ and $97 \%$ of the subjects, respectively, for three-cause and two-cause items.

\section{Discussion}

The results of Experiments 1 and 2 were highly consistent with either a serial or truncated information search in multicausal explanation. Information suggesting that a possible cause contributed to an event focused attention on that cause. Questions clarifying the role of that cause were greatly preferred by explainers.

There is no logical reason why people in any of these conditions should not ask questions about any of the possible causes. Without an implicating fact, subjects are uncertain about the roles of all possible causes. Although the facts that were given did implicate particular causes, they did not make the roles of those causes entirely clear. Thus, a question about the implicated cause could still reduce uncertainty, although not necessarily as much as a question about the other possible causes.

One possible interpretation of this pattern of results would be that subjects believed for some reason that only one cause could be involved in each event. The instructions gave no indication that this was the case, telling subjects only that "your task is to explain why the event occurred." A substantively interesting reason why subjects might have assumed that only one cause could be involved would be that, for each item, finding that one cause was implicated led them to discount the possibility of another cause being involved. Such a propensity for unicausal explanations would certainly be a process contributing to nonparallel search, or even a disinclination to search at all. Why look further if one already has evidence supporting a particular cause's involvement?

An uninteresting reason for assuming that only one cause was involved would be that the instructions or task formulation somehow hinted that no more than one cause could be involved in the event. The implicated cause would then be the likely candidate. Experiment 3 took two separate steps to investigate this possible problem. One was simply to tell subjects explicitly that "in each item, one or more of the possible causes may have contributed to the event." The second was to ask subjects who had received a fact to evaluate the extent to which each of the listed causes had been responsible for the event. Performing this subtask should remind subjects that multiple causation is not only possible, but presumed to occur.

\section{EXPERIMENT 3}

\section{Method}

The Fact 1 and no-fact questionnaires used in Experiment 2 were used here, with the following changes: (1) Immediately following the example giving an event and three possible causes, the general instructions of each questionnaire informed subjects that "in each item, one or more of the possible causes may have contributed to the event," and (2) each of the last eight questions included a causal attribution task designed to remind subjects of the possibility of multiple causation. Specifically, after subjects had picked the question whose answer they most desired, they were asked the questions shown in Figure 2.

These questions were added to only a portion of the items because they greatly increased subjects' work load. Only one fact form was used because results had been so similar on the two forms in Experiment 2. The attribution task followed the question selection task because the latter was of primary interest to us. In case subjects felt any need to make their responses on the two tasks rigorously consistent, we preferred to have them distorting the attributions to justify their question selection than vice versa.

Subjects. Subjects were 65 individuals recruited from a state employment agency and paid for completing the present task and several other unrelated tasks. The fact form was completed by 32 subjects, and the no-fact form by 33 subjects.

On the basis of the evidence that you already have received, we would like you to decide what caused the event to occur. Do this by dividing $100 \%$ of causal responsibility over the listed causes. These percentages indicate the extent to which each caused the event.

Possible Cause

\% Causal Responsibility

A. He has a penchant for fast driving

B. He was late

C. He was framed

D. Other causes

You can divide the $100 \%$ however you feel appropriate. For example, you need not attribute any responsibility to a category if you think that it can be ruled out.

Figure 2. Questions asked in Experiment 3. 


\section{Results}

The first 11 items of each form were replicates of the comparable items of Experiment 2, except that they were answered in the context of instructions that made the possibility of multiple causation explicit. For 9 of these 11 comparisons, fact subjects who had received factual information implicating a cause were more likely to select the question relevant to that cause than were no-fact subjects. Over the 11 cases, fact subjects selected the question about the implicated cause $65.3 \%$ of the time, compared to $41.3 \%$ selecting the same questions when no fact was given.

Similar results were obtained with the remaining eight items, which emphasized the possibility of multicausality by having subjects make multicausal attributions. For all eight items, the question related to the implicated cause was more popular for fact than for nofact subjects; it was chosen $66.4 \%$ of the time by the former and $47.7 \%$ of the time by the latter. ${ }^{3}$

As an indirect manipulation check, we did two simple analyses on subjects' causal attributions. One of these revealed that subjects assigned $0 \%$ responsibility to a proposed possible cause only $13.0 \%$ of the time on the no-fact form and $13.4 \%$ of the time on the fact form, indicating that they realized that multiple causation was possible. In the fact condition, nonimplicated causes were assigned a zero $18.7 \%$ of the time and implicated causes $5.1 \%$ of the time, suggesting a modest tendency to discount nonimplicated causes. The second analysis revealed that the implicated causes in the four two-cause items received a mean attribution of $56.2 \%$ in the fact form, but only $48.5 \%$ in the no-fact form. The four three-cause items showed the same pattern, with a mean attribution of $46.6 \%$ in the fact form, $34.8 \%$ in the no-fact form.

\section{Discussion}

Subjects continued to prefer questions about implicated causes under conditions in which instructions explicitly indicated that multiple causes might be involved. Furthermore, outright rejection of a nonimplicated cause in attribution ratings was a rare response. A fact implicating a cause led subjects to rate that cause as bearing a higher proportion of the causal responsibility, but the other proposed causes were generally assigned a share of the causal influence as well. Thus, the obtained preference patterns in this and the previous studies seem not to be an artifact of some subtle implication in instructions or format that only one cause could be involved in the event.

As noted previously, the observed preference for questions about implicated causes is congruent with both the serial and truncated search models. In either case, information about the implicated cause is solicited in order to clarify residual ambiguity about its role. However, predictions of the two models diverge once the role of that cause has been adequately resolved. The serial information searcher would begin investigating other potential causes, whereas the truncated searcher would find those other potential explanations irrelevant. As a result, the truncated searcher would either continue to focus on the known cause (e.g., clarifying just how it led to the event) or stop searching altogether if that is possible. Thus, discriminating between these two strategies requires looking at information search once one cause is known to have contributed to the event. Experiment 4 investigates judgment under such conditions. A truncated search would result in questions about the known cause, whereas a serial strategy would lead to questions about the other cause(s).

\section{EXPERIMENT 4}

\section{Method}

Stimuli. Events, causes, and questions about the events were the same as those used in Experiments 2 and 3 . Implicating facts were omitted. Instead, one cause for each item was labeled as a known cause of the event; the others were labeled possible causes. The two known-cause forms (Forms 1 and 2) varied the labels of known and possible causes. A comparison (possiblecause) form listed all causes as possibilities. This form was identical to the no-fact form of Experiment 2 . The suggested causes were followed by a set of questions, one of which was relevant to each of the two or three causes.

Instructions. As in Experiment 3, instructions noted that more than one cause might be involved in the event. Instructions for the known-cause form are shown in Figure 3.

Subjects. Subjects were students in an introductory psychology class who participated in the experiment as one option in fulfillment of a class requirement. Subjects were randomly assigned to one of the three conditions, with 29 people responding to each of the three forms.

\section{Results}

Again, 19 events on two different forms afforded 38 comparisons between the known-cause and possiblecause forms. In 28 of the 38 comparisons, subjects were

Each of the problems in this booklet describes an event and several possible causes of that event. Your task is to explain why the event occurred.

Event: Jim was arrested for speeding.

Possible Cause A: He was late.

Possible Cause B: He was framed.

Known Cause: He has a penchant for fast driving.

For each item, the known cause definitely contributed to the event. Each possible cause may have also contributed to the event. After each event, two or three questions about that event are listed. For example, for the above item, you might have questions:

Question 1: What's Jim's past speeding record?

Question 2: Was the arresting officer short on the number of traffic citations he'd given that night?

Question 3: When was Jim supposed to be at his destination?

Your task is to identify which of those questions you would most like to have answered in trying to explain why Jim was arrested for speeding. In the space provided for each item, write the number $(1,2$, or 3$)$ of the question you'd most like answered in explaining the event.

Figure 3. Instructions for the known-cause form in Experiment 4 . 
Table 4

Differences in Percentages of Known Cause and Possible Cause Subjects Selecting Questions About Target Causes (=X): Experiment 4

\begin{tabular}{cc}
\hline Difference & Frequency \\
\hline $\mathrm{X} \leqslant-15 \%$ & 3 \\
$-15 \%<\mathrm{X} \leqslant 0 \%$ & 7 \\
$0 \%<\mathrm{X} \leqslant 15 \%$ & 5 \\
$15 \%<\mathrm{X} \leqslant 30 \%$ & 9 \\
$30 \%<\mathrm{X} \leqslant 45 \%$ & 8 \\
$45 \%<\mathrm{X} \leqslant 60 \%$ & 4 \\
$60 \%<\mathrm{X}$ & 2 \\
\hline
\end{tabular}

more likely to request information about a cause when it was a known cause than when it was a possible cause of an event, consistent with truncated search. Across all items, subjects selected the question about the known cause $61.8 \%$ of the time on the known-cause forms, but only $41.8 \%$ of the time on the possible-cause form. Table 4 gives a frequency distribution of the size of preference shifts for the 38 comparisons. Differences between preferences for the target question on the two forms were significant for 17 comparisons (chi-square test, $a=.05$ ), all but one of which was in the direction predicted by the truncated search model.

Question preferences within items on known-cause Forms 1 and 2 showed the same pattern. Questions about known causes were preferred over questions about other causes in 28 of the 38 cases.

Looking at individual subjects, $80.8 \%$ showed greater than chance preference for questions about the known cause when judging both two-cause and three-cause items.

\section{Discussion}

Certainty about the role of one cause should lead serial searchers to investigate other possible causes. However, Experiment 4 subjects did not exhibit this pattern. Instead, they continued to prefer questions about an implicated cause even when its implication was certain, consistent with a truncated information search. Such questions about a known cause may not be entirely uninformative. That is, a subject may learn some detail about that cause, such as the manner in which it had its effect. In the example given in Figure 3, subjects do not know if Jim has a speeding record even though they know he has a penchant for fast driving. The results of this experiment suggest that subjects who know that a cause is involved in an event prefer to learn such additional details about that cause, rather than learning about other causes that might also have influenced the event. Attention is drawn to the known cause, resulting in reduced interest in other possible causes.

An important implication of using a truncated search strategy is the potential loss of relevant information. Having discovered that one cause is involved in an event, this individual is unlikely to discover that other causes may be involved as well. Identification of a sufficient explanation may be enough to placate the attributor's interest, but an incomplete account will leave him or her in a poor position to control the event of interest. For example, a mother who discovers that her child's tantrums are aggravated by a sibling's presence has leamed only one of several potentially important determinants of the behavior of interest. Maximally effective intervention in the tantrum behavior would require identification of the full set of its causes.

A final question of interest may be that of the generality of the strategy. Subjects in these experiments selected only one question about each event, a situation that is a representation of many real-life situations in which limited time or interest may restrict one's search. On other occasions, however, a more elaborate information search may be possible. Multiple questions might be used to elicit a set of informational clues that can be weighted in deriving an explanatory account. Experiment 5 examines information search patterns when subjects have an opportunity to make a more extended search. Parallel search subjects should sample questions about alternative causes throughout the search period, whereas nonparallel searchers should continue to ask about initially implicated causes.

\section{EXPERIMENT 5}

\section{Method}

Stimuli. Each of the four items consisted of a statement of an event, two possible causes of the event, a fact relevant to one of the two causes, and eight questions about the event. Four of the questions asked for information relevant to one cause; four questions asked about the other cause. For each item, questions were sequenced randomly. An example item is shown in Figure 4.

As before, there were two fact forms (Forms 1 and 2), differing in the cause implicated by the fact in each item. A third form (no fact) presented the same items with no fact.

Pretest. A sample of 26 subjects judged each of the facts as relevant to Cause 1, Cause 2, both causes, or neither cause. Facts were retained if $70 \%$ or more of the sample agreed about

Event: Ruth took a summer job as a camp counselor.

Possible Cause 1: She loves out-of-doors recreation.

Possible Cause 2: She loves working with children.

Fact: Ruth just finished a course in mountaineering.

Importance

Ranking Questions

_ Has Ruth done much camping?

Does Ruth do any volunteer work with children?

Does Ruth have many outdoor hobbies?

Does Ruth like physical exercise?

Does Ruth like to babysit?

Does Ruth like to spend time with her friends' kids?

Does the camp emphasize outdoor skills?

Does Ruth deal effectively with children in groups?

Figure 4. Example of items used in Experiment 5. 
the cause implicated by the fact. Questions about the causes were pretested in a similar fashion, with samples of 29-64 subjects judging each question as most informative about Cause 1, Cause 2, both causes, or neither of the two causes. A question was retained if $70 \%$ or more of the subjects agreed as to the cause about which it was most informative. Mean agreement about the causal referent of the facts and questions on the four items used was $81.0 \%$ and $85.4 \%$, respectively.

Instructions. Instructions to the subjects were as follows (with mention of the fact being omitted on the no-fact form): "Each problem in this booklet describes an event, a fact about that event, and two possible causes of that event. Your task is to explain why the event occurred. After each event, eight questions about the event are listed. We'd like you to number the questions from one to eight in the order of their potential importance in helping you account for why the event occurred $(1=$ most important, $8=$ least important). First, choose the question whose answer would be most important to you in explaining the event and write a 1 in the space provided. Then, choose the next most important question and write a 2 in the space provided. Write a 3 in the space in front of the third most important question, and so on, until all of the questions are ranked. The least important question would then get an $8 . "$

Subjects. Subjects were members of an introductory psychology class who participated in the experiment as one option in fulfillment of a course requirement. The Fact 1 , Fact 2 , and no-fact forms were completed by 32,34 , and 30 subjects, respectively.

\section{Results}

Since the importance rank orders for questions within each item are interdependent, analyses were done on subjects' overall tendency to prefer questions referring to each cause. For each item, a subject's question preference was characterized as the difference between the mean rank of questions about Cause 1 and the mean rank of questions about Cause 2. Mean ranks for questions about each cause are listed in Table 5. Lower mean ranks reflect more important questions. Parallel search would lead to comparable difference scores with the two forms. There might be an overall tendency to prefer Cause 1 or Cause 2 questions (i.e., because they were better questions), but any such preference should not be affected by which cause was implicated. Non-

Table 5

Mean Ranks for Questions About Each Cause: Experiment 5

\begin{tabular}{cccc}
\hline \multirow{2}{*}{ Item 1 } & Questions About & $\begin{array}{c}\text { Cause 1 } \\
\text { Implicated }\end{array}$ & $\begin{array}{c}\text { Cause 2 } \\
\text { Implicated }\end{array}$ \\
\hline \multirow{2}{*}{ Item 2 } & Cause 1 & 4.77 & 5.68 \\
& Cause 2 & 4.23 & 3.32 \\
Item 3 & Cause 1 & 4.11 & 4.79 \\
& Cause 2 & 4.89 & 4.15 \\
Item 4 & Cause 1 & 4.19 & 4.99 \\
& Cause 2 & 4.80 & 4.01 \\
& Cause 1 & 4.86 & 5.28 \\
& Cause 2 & 4.13 & 3.72 \\
\hline
\end{tabular}

Note-Eight causes were ranked. Lower mean ranks indicate that questions about a particular cause tended to be selected earlier. The maximum possible discrepancy between mean ranks for the two kinds of questions was 2.5 vs. 6.5 (when all questions of one kind were always among the first four selected).

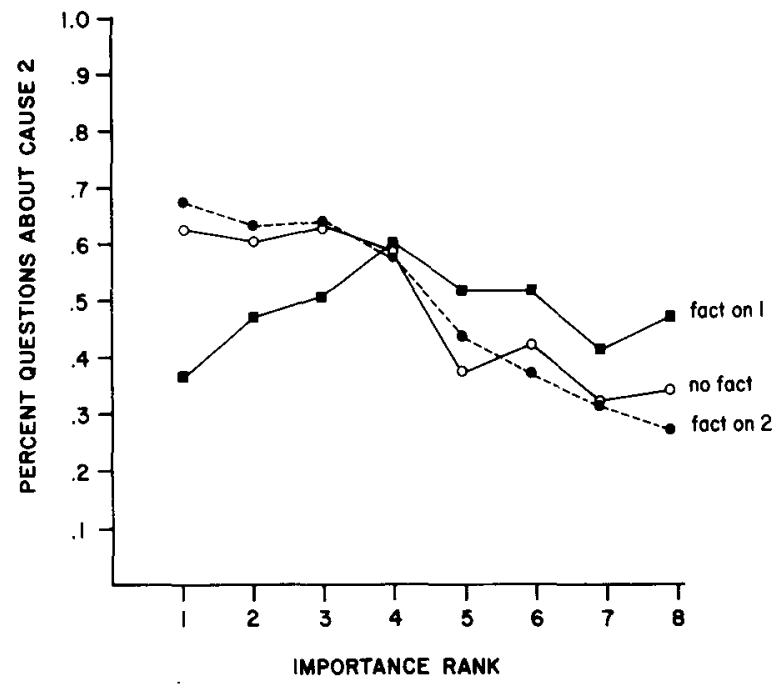

Figure 5. Percentage of subjects asking questions about Cause 2 among subjects receiving a fact implicating Cause 1 (squares), a fact implicating Cause 2 (closed circles), or no fact (open circles) in Experiment 5.

parallel search should increase the relative preference for Cause 1 questions when Cause 1 is implicated and decrease it when Cause 2 is implicated. All four items showed such a pattern; 3 of these differences were statistically significant $[\mathrm{t}(64) \geqslant 2.48, \mathrm{p}<.05]$, whereas the fourth fell short of significance $[\mathrm{t}(64)=1.53$, n.s.]

An alternative perspective on the data is afforded by the sequence of question selections. In a task like the present one, in which all eight questions must be ranked, a serial or truncated question search would result in initial questions' focusing on the implicated cause and later questions' asking about the other one. Figure 5 shows the percentage of subjects asking questions about Cause 2 as a function of importance rank. Initial preference for Cause 2 questions is high when Cause 2 is the implicated cause, tapering off at the later ranks. For example, $69 \%$ of subjects' first choices were for questions about Cause 2, compared with $28 \%$ of their eighth choices. A reverse trend emerges when Cause 1 is the implicated cause. Question rankings on the no-fact form fall in between the trends on the two fact forms. The greater similarity of the no-fact to the Fact 1 curve indicates that the facts about the (arbitrarily labeled) Cause 1s did more to enhance interest in the relatively unattractive questions about the Cause 1s than the facts about the Cause $2 \mathrm{~s}$ did for their respective questions.

\section{GENERAL DISCUSSION}

The final experiment demonstrated that the preference for information about implicated causes persists even when subjects have an opportunity to sample several questions about both possible causes. Once 
again, subjects preferred to clarify the role of one cause before considering others. The format of that experiment forced respondents eventually to choose all questions. It is difficult to say, however, to what extent people in less restrictive circumstances would actually proceed to ask questions about other causes. Experiment 4 indicated that people often may not ask about the role of additional causes even when the first cause is known to have contributed to an event. Thus, questions later in the importance hierarchy might never be raised. A truncated search of this sort should be especially likely when time is limited or motivation is low.

The explanatory account produced by a truncated search obviously runs the risk of incompleteness. It may, in addition, lead to emphasizing a cause of marginal importance. Many factors can lead to an early preference for one account of an event (e.g., implicating information, past experience, prejudices, self-enhancing biases). There is no guarantee that this front runner is central to the event, even if subsequent questions "prove" its involvement. For example, the importance of particularly salient causes would tend to be overestimated (Taylor \& Fiske, 1978). If, as suggested earlier, the interpretation of such evidence as it is received is biased toward signs of consistency with the initially favored cause, a truncated search would result in particularly limited information gathering.

Although a suboptimal approach to understanding events fully, a truncated search would serve to simplify them greatly. The basis for that simplification could reflect an interaction between cognitive limitations and the structure of everyday experience. Since an event will occur once a sufficient cause is present, the role of additional possible causes is hard to assess. Given the difficulty (sometimes impossibility) of controlling or manipulating causes in the real world, naive observers must settle for some approximate representation of the cause-effect relationships with which they commonly deal. By focusing on single sufficient causes, people identify the simplest interpretation congnent with their experiences. Thus, the strategy may be seen as another example of a judgmental heuristic (Tversky \& Kahneman, 1974) that is often useful, but which can lead one astray. Alternatively (or additionally), the strategy could be motivationally based. Scientists attempt to identify all contributing causes in order to maximize their ability to predict and control events. Naive observers, however, may have a more modest goal of "making sense" out of the environment. Once an event is adequately accounted for, the search for other causes may often become superfluous.

\section{REFERENCES}

Fischног, B. Attribution theory and judgment under uncertainty. In J. Harvey, W. Ickes, \& R. Kidd (Eds.), New directions in attribution research (Vol. 1). Hillsdale, N.J: Erlbaum, 1976.

Hansen, R. Commonsense attribution. Journal of Personality and Social Psychology, 1980, 39, 996-1009.
Jones, E., \& Davis, K. From acts to dispositions: The attribution process in person perception. In L. Berkowitz (Ed.), Advances in experimental social psychology (Vol. 2). New York: Academic Press, 1965.

Jones, E., \& McGlllis, D. Correspondent inferences and the attribution cube: A comparative reappraisal. In J. Harvey, W. Ickes, \& R. Kidd (Eds.), New directions in attribution research (Vol. 1). Hillsdale, N.J: Erlbaum, 1976.

KELLEY, H. Attribution theory in social psychology. In D. Levine (Ed.), Nebraska Symposium on Motivation. Lincoln: University of Nebraska Press, 1967.

Kelley, H. Attribution in social interaction. Morristown, N.J: General Learning Press, 1972. (a)

KELLEY, H. Causal schemata and the attribution process. Morristown, N.J: General Learning Press, 1972. (b)

Kun, A., Murray, J., \& Sredi, K. Misuses of the multiple sufficient causal schema as a model of naive attributions: A case of mistaken identity. Developmental Psychology, 1980, 16, 13-22.

MAJOR, B. Information acquisition and attribution processes. Journal of Personality and Social Psychology, 1980, 39, 10101023.

Schustack, M., \& Sternberg, R. Evaluation of evidence in causal inference. Journal of Experimental Psychology: General, 1981, 110, 101-120.

Sмгтн, M. Children's use of the multiple sufficient cause schema in social perception. Journal of Personality and Social Psychology, 1975, 32, 737-747.

SnYder, M., \& Swann, W. B. Hypothesis-testing processes in social interaction. Journal of Personality and Social Psychology, 1978, 36, 1202-1212.

TAPLIN, J. Evaluation of hypotheses in concept identification. Memory \& Cognition, 1975, 3, 85-96.

TAYLOR, S. E., \& Fiske, S. T. Salience, attention and top of the head phenomena. In L. Berkowitz (Ed.), Advances in experimental social psychology (Vol. 11). New York: Academic Press, 1978.

TVERsky, A., \& KahNeman, D. Judgment under uncertainty: Heuristics and biases. Science, 1974, 185, 1124-1131.

Wason, P. C., \& Johnson-Laind, P. N. Psychology of reasoning. Cambridge, Mass: Harvard University Press, 1972.

\section{NOTES}

1. A confirmatory bias would lead searchers to be more interested in substantiating the role of the initially favored hypothesis in evaluating it fairly. For example, they might ask primarily questions whose anticipated answers will be consistent with that hypothesis, failing to note that they are also consistent with alternative hypotheses. Although such a tendency would represent a bias in interpretation, it would be facilitated by a serial information search strategy and encourage premature truncation of that search.

2. The two fact groups considered different facts (and different implicated causes) for each event. As a result, the overall percentage of cases in which no-fact subjects selected questions about causes implicated by facts given to the two no-fact groups could not have been higher than $50 \%$. The percentage observed (43.6\%) means that $6.4 \%$ of no-fact subjects' selections were for questions about the one cause in three-cause items for which an implicating fact was not presented to either fact group. The comparable selection rate for fact subjects could assume any value from $0 \%$ to $100 \%$. Similar comments apply to Experiments 3 and 4 .

3. A look at comparable items in Experiment 2 shows that, on the first 11 items, $83.5 \%$ of subjects selected questions about the implicated cause on the Fact 1 form, and $43.5 \%$ selected the same questions on the no-fact form. On the last eight items, subjects preferred questions about implicated causes $82.7 \%$ of the time on the Fact 1 form and $50.0 \%$ of the time on the nofact form. 


\section{APPENDIX \\ ITEMS USED IN EXPERIMENTS 14}

Note that the 20 items in Experiment 1 include these 19 items in addition to 1 other item that was dropped in later experiments for failing to meet pretest criteria in Experiment 2. Questions about events were omitted in Experiment 1. Facts were omitted in Experiment 4, and one possible cause in each item was labeled "Known Cause."

1. Event: Tim advertised for a roommate to share his apartment.

Possible Cause A: Tim's rent was too much for him to continue paying alone.

Possible Cause B: Tim had been feeling lonely and wanted company at home.

Possible Cause C: The crime rate in Tim's neighborhood had been increasing.

Form 1 Fact: Tim's scholarship had recently been cut back due to university budgetary problems.

Form 2 Fact: His long-time steady had recently broken with him.

Question 1: Had other apartments in Tim's building been burglarized?

Question 2: How much is Tim's rent?

Question 3: Does Tim have very many friends?

2. Event: Tony got his hair cut.

Possible Cause A: He wanted to look more conservative for job interviews.

Possible Cause B: He was afraid of going bald and felt that his hair needed the stimulation.

Form 1 Fact: He was generally quite vain.

Form 2 Fact: He was in his senior year.

Question 1: Does baldness run in Tony's family?

Question 2: What kind of job is Tony looking for?

3. Event: Bill was stopped by the police for driving $10 \mathrm{mph}$ over the speed limit.

Possible Cause A: Bill was hurrying to get to an appointment on time.

Possible Cause B: Bill had a defective speedometer.

Form 1' Fact: He had had the same car since high school.

Form 2 Fact: He had a reputation for getting places on time.

Question 1: Where was Bill going?

Question 2: Was Bill aware that he was speeding?

4. Event: Susan made a $\$ 25$ donation to a cancer research fund.

Possible Cause A: Someone close to Susan recently died of cancer.

Possible Cause B: Susan of ten gives money to charity.

Form 1 Fact: She is quite wealthy.

Form 2 Fact: She had known the friend since kindergarten.

Question 1: In whose name did Susan give the money?

Question 2: To what other foundations does Susan contribute?

5. Event: Joe got $95 \%$ correct on his history final.

Possible Cause A: The final was easy.

Possible Cause B: Joe is particularly good at history.

Possible Cause C: Joe had studied very hard for the final.

Form 1 Fact: It was known as a snap course.

Form 2 Fact: Getting a good grade on that exam was critical to getting off probation.

Question 1: Does Joe like history?

Question 2: How much in advance did he begin to prepare for it?

Question 3: How did the other students do on the final?

6. Event: Jim's car swerved out of control on the freeway.

Possible Cause A: The car had a blowout.

Possible Cause B: Jim had drunk enough alcohol to impair his driving.

Possible Cause C: The car had been hit from behind.
Form 1 Fact: It had been months since he'd had his car in the shop to be looked over.

Form 2 Fact: The accident happened during rush hour traffic.

Question 1: Was the car behind Jim following too closely?

Question 2: How quick were Jim's reflexes at the time?

Question 3: How old were Jim's tires?

7. Event: Marie declined an invitation from Alice to have dinner at her house.

Possible Cause A: Marie doesn't like Alice's cooking.

Possible Cause B: Marie never went out.

Form 1 Fact: She wasn't willing to do anything else.

Form 2 Fact: Marie considered herself a connoisseur.

Question 1: How many times had Marie eaten at Alice's before?

Question 2: Was Marie shy?

8. Event: Diane rode her bike to work.

Possible Cause A: Diane's car wouldn't start.

Possible Cause B: There were no parking places on campus.

Form 1 Fact: It was below freezing.

Form 2 Fact: Even in bad weather, she rode her bike.

Question 1: Had Diane's car been giving her trouble lately?

Question 2: Did Diane ride her bike for convenience?

9. Event: Ernest moved out of his apartment building and into a house.

Possible Cause A: He wanted to get away from his noisy neighbors.

Possible Cause B: He wanted a yard where he could plant a garden.

Possible Cause C: He had moved many times in the previous year.

Form 1 Fact: The apartment housed mainly students.

Form 2 Fact: He was known for his wild parties.

Question 1: Did Ernest tend to have poor relationships with his landlords?

Question 2: Did his neighbors tend to party much?

Question 3: Had Ernest enjoyed gardening in the past?

10. Event: John spent the afternoon helping Gary paint his house.

Possible Cause A: Gary had done him a similar favor recently.

Possible Cause B: Gary had lots of painting to do and really needed help.

Possible Cause C: John had time on his hands.

Form 1 Fact: John was an unemployed painter.

Form 2 Fact: Gary had just moved.

Question 1: Had John been involved in a big work project recently?

Question 2: Was Gary remodeling his house?

Question 3: Was John bored?

11. Event: Margaret took in a stray kitten.

Possible Cause A: Her own kitten seemed to need company.

Possible Cause B: It was an affectionate kitten.

Possible Cause C: It resembled a kitten she had had when she was young.

Form 1 Fact: Margaret is away from home all day.

Form 2 Fact: The kitten had followed her home.

Question 1: Does Margaret own any other animals?

Question 2: Did Margaret grow up with animals?

Question 3: Does the kitten like to be petted?

12. Event: Tom sold his downhill skis and boots.

Possible Cause A: Downhill skiing was getting too crowded for him to enjoy.

Possible Cause B: He needed money for tuition.

Possible Cause $\mathrm{C}$ : He was planning to buy downhill skiing equipment.

Form 1 Fact: He had been skiing since the early 1960s.

Form 2 Fact: He also sold his stereo.

Question 1: How much money did he get for them?

Question 2: Does Tom like cross-country skiing?

Question 3: How old were the skis and boots? 
13. Event: Bill and Mary postponed their plans to camp for a couple of weeks.

Possible Cause A: The weather was too cold to enjoy spending much time outside.

Possible Cause B: Bill had a backlog of work to complete before he could take time off.

Possible Cause C: They hadn't saved up enough money yet.

Form 1 Fact: Bill had just gotten a manuscript back from his publisher.

Form 2 Fact: Over the winter they had had to replace their car.

Question 1: What month of the year was it?

Question 2: How much would this trip cost?

Question 3: Would Bill have more time in a couple of weeks?

14. Event: Ellen lost her match in the tennis tournament.

Possible Cause A: Her opponent had an especially good serve.

Possible Cause B: She was still a little weak from a recent bout with the flu.

Form 1 Fact: She knew that she was in over her head when she signed up for the tournament last fall.

Form 2 Fact: She hadn't played in over a month.

Question 1: How long had her opponent been playing tennis?

Question 2: How long ago had Ellen been sick?

15. Event: Matt decided to stop eating meat.

Possible Cause A: He thought he might be healthier on a vegetarian diet.

Possible Cause B: Meat prices had risen beyond the range of his food budget.

Possible Cause C: He had just read Sinclair's "The Jungle," an expose of meat packing.

Form 1 Fact: Most of his friends were vegetarians.

Form 2 Fact: He had told his friends it wasn't an ideological decision.

Question 1: How much money did Matt have to spend on food?

Question 2: Had Matt been feeling less than healthy?

Question 3: Was Matt interested in consumer protection issues?

16. Event: Louise called long distance to her mother.

Possible Cause A: It was her mother's birthday.
Possible Cause B: She had just been accepted to graduate school and wanted to share the good news.

Possible Cause C: She didn't have the time to write.

Form 1 Fact: It was the busiest time of the year for her.

Form 2 Fact: Her mother wasn't surprised at the call.

Question 1: How long ago did Louise apply to graduate school?

Question 2: Had Louise taken a heavy course load at school?

Question 3: Did Louise call her mother on her last birthday?

17. Event: Laura bought a pantsuit.

Possible Cause A: She needed more clothes she could wear to work.

Possible Cause B: The pantsuit was on sale.

Form 1 Fact: She was on her first job out of college.

Form 2 Fact: She tended to impulsivity.

Question 1: How much did the pantsuit cost?

Question 2: Had Laura gone shopping with the intent to buy clothes?

18. Event: Robert got behind in the required work for his English class.

Possible Cause A: Robert was sick for a week that term.

Possible Cause B: Robert was always behind in his work.

Form 1 Fact: It was the second time he had taken the class.

Form 2 Fact: It was the winter term.

Question 1: What was Robert's health like?

Question 2: Does Robert have problems organizing his time?

19. Event: Tim left a big tip for the waiter at dinner.

Possible Cause A: The waiter did an especially good job.

Possible Cause B: Tim wanted to impress his dinner companion with his generosity.

Form 1 Fact: Tim regularly came to that restaurant.

Form 2 Fact: His companion was the president of the company he worked for.

Question 1: What was the purpose of dinner with this particular companion?

Question 2: Did the waiter get big tips from other tables?

(Received for publication August 21, 1981; revision accepted April 1, 1982.) 